\title{
Endogenous Transportation Technology in a Cournot Differential Game with Intraindustry Trade
}

\author{
Luca Colombo, Luca Lambertini†and Andrea Mantovani ${ }^{\ddagger}$
}

September 2, 2003

\begin{abstract}
We investigate a dynamic Cournot duopoly with intraindustry trade, where firms invest in $\mathrm{R} \& \mathrm{D}$ to reduce the level of iceberg transportation costs. We adopt both open-loop and closed-loop equilibrium concepts, showing that a unique (saddle point) steady state exists in both cases. In the open-loop model, optimal investments and the resulting efficiency of transportation technology are independent of the relative size of the two countries. On the contrary, in the closed-loop case, a home market effect operates so that the firm located in the larger country invests more than the rival located in the smaller one. Policy implications are also evaluated.
\end{abstract}

JEL classification: C73, D43, F12, L13, O31.

Keywords: R\&D, differential games, transport and communication costs, intraindustry trade.

*Department of Economics, University of Bologna, Strada Maggiore 45, 40125 Bologna, Italy; email: colombo@spbo.unibo.it.

${ }^{\dagger}$ Department of Economics, University of Bologna, Strada Maggiore 45, 40125 Bologna, Italy; email: lamberti@spbo.unibo.it.

‡CORE, Université Catholique de Louvain, 34 voie du Roman Pays, B-1348, Louvain-la-Nueve, Belgium; and Department of Economics, University of Bologna, Strada Maggiore 45, 40125 Bologna, Italy; email: mantovan@spbo.unibo.it. 


\section{Introduction}

Transport and communication costs are at the heart of many international trade issues because they put a wedge on transactions across borders. The traditional view is that national borders affect trade because their existence is associated with discriminatory policies and physical distance. In this framework distance is not conceived only in terms of physical space, but it also includes a broad category of features such as language, different legal systems across borders, local consumer tastes, i.e., everything that may constitute an economic and social impediment for the exporting firm.

Starting from McCallum (1996), recent empirical research on trade reveals a surprisingly high degree of market fragmentation that gives rise to border effects and to the so-called "home bias" effect. Obstfeld and Rogoff (2000) refers to the home bias as one of the "six major puzzles in international macroeconomics". In their view, the interaction between iceberg transport costs and the elasticity of substitution between domestic and foreign goods accounts for much of the observed home bias. Anderson and Marcouiller (1999) propose a different explanation for the home bias, relying on the consideration that the rule of law is much weaker when trade is international. Along the same line, Turrini and van Ypersele (2002) point out that the home bias can be explained by differences in legal systems, so that legal costs are higher when business is done abroad rather than at home.

Nonetheless, the issue of transport costs has not received sufficient attention in the literature, perhaps because of steadily declining communication and shipment costs. ${ }^{1}$ However, the persistence of many home biases confirms that the question of transport costs is not a secondary one and needs further and deeper investigations.

In this paper, we analyze the strategic behavior of firms located in different countries that open up to trade and face an additional cost when delivering abroad. As a stylized fact, firms that export their goods abroad face costs that are not only due to

\footnotetext{
${ }^{1}$ Harley (1980) and O'Rourke and Williamson (1999) document the sharp declines in both ocean and overland transportation costs.
} 
physical distance, but also to the access to a foreign network of communication and distribution. Hence, they might be willing to invest in transport and communication technology to increase the penetration into foreign markets.

We consider a duopoly Cournot game with firms facing the possibility of investing in transport and communication R\&D (TCRD). By investing in TCRD, a firm may have an easier access to the foreign market, thus increasing her market share. As usual, transport and communication costs are of the 'iceberg' form introduced in the literature by Samuelson (1954) and widely used in trade theory thereafter.

Both the open-loop and the closed-loop equilibria are investigated. ${ }^{2}$ In the former, the resulting steady state investment efforts and the efficiency levels of transportation technologies depend only upon time discounting, depreciation and the efficiency of TCRD. This is due to the fact that, in the open-loop setting, firms design an investment plan at the outset and stick to it until they reach the steady state, regardless of the strategic interaction taking place in between. Accordingly, the relative size of the two countries does not influence the investment behaviour and the resulting performance of firms' transportation technologies at equilibrium. On the contrary, in the closed-loop equilibrium firms explicitly account for strategic interaction through reciprocal feedback effects at any point in time. This yields optimal investment efforts and equilibrium technologies that do depend upon the relative size of the two markets. In particular, each firm's optimal investment path toward the equilibrium is positively affected by the size of the foreign country, all else equal. This can be labelled as a 'foreign market effect', for the sake of contrasting this finding with the well known 'home market effect' whereby a firm located in the larger market sells more than the firm located in the smaller market (see Krugman, 1990, inter alia). When firms only control sales in order to maximise profits, then, intuitively, market shares on the international market place go along with the relative size of countries.

\footnotetext{
${ }^{2}$ For an introduction to differential oligopoly games, see Cellini and Lambertini (2003). For a more detailed treatment of differential game theory, see Dockner et al. (2000).
} 
However, if firms are required or allowed to endogenously determine their respective ability to reach the foreign market, then the size of the latter may matter more than the size of the home market.

On the other hand, we find that the larger is the home market, the lower will be the efficiency of the transportation technology employed by a firm in the closedloop steady state equilibrium. This reveals the presence of a 'home market effect' operating at equilibrium. This can be interpreted in the usual sense, as the funds for $\mathrm{R} \& \mathrm{D}$ activities are raised by sales, which in turn are positively affected by the size of the domestic country.

A domestic policy maker aiming at improving his country's social welfare may adopt two alternative measures (or a combination of both). He may modify either the instantaneous cost of investment, or the efficiency of the R\&D technology, through subsidies or taxation. In both cases, a taxation policy should be adopted so as to reduce excess investment characterising the closed-loop equilibrium. ${ }^{3}$

The remainder of the paper is organized as follows. The setup is laid out in section 2. Open-loop and closed-loop equilibria are investigated in section 3. Section 4 analyses policy implications. Concluding remarks are given in section 5 .

\section{The model}

We consider a model of bilateral trade between two firms selling a homogeneous good. We assume that firm $i$ is located in country $A$ while firm $j$ is located in country $B$. Market competition takes place as a Cournot game where each firm chooses the profit maximizing quantity for each country separately (Brander, 1981). Time is continuous and denoted by $t$, with $t \in(0, \infty)$.

Firms face an additional transport cost only when shipping the final good abroad.

\footnotetext{
${ }^{3}$ This phenomenon is widely accounted for in the literature since Brander and Spencer (1983). We don't dwell upon the possibility for a policy maker to adopt tariffs or quotas, in view of the recent guidelines of GATT and WTO.
} 
This amounts to saying that transport costs only affect international trade. We model transportation costs as in Samuelson (1954), i.e. using the iceberg metaphor.

Consider the following indirect demand system:

$$
\begin{aligned}
& p_{A}(t)=a_{A}-q_{i A}(t)-\frac{q_{j A}(t)}{s_{j}(t)} \\
& p_{B}(t)=a_{B}-q_{j B}(t)-\frac{q_{i B}(t)}{s_{i}(t)}
\end{aligned}
$$

where $q_{i A}(t)\left(q_{j B}(t)\right)$ denotes the quantity produced by firm $i(j)$ for domestic consumption and $q_{j A}(t)\left(q_{i B}(t)\right)$ represents the quantity produced by firm $j(i)$ for foreign consumption; $\frac{q_{j A}(t)}{s_{j}(t)}$, with $s_{j}(t)>1 \forall t \in[0, \infty)$, represents the share of firm $j$ 's good that arrives in country $A$ at time $t$, and similarly for $\frac{q_{i B}(t)}{s_{i}(t)}$. Finally, $a_{A}$ and $a_{B}$ stand for market-sizes, both supposed to be constant over time.

On the supply side, production exhibits constant return to scale. For the sake of simplicity, we normalize unit costs to zero. Instantaneous profits are then given by:

$$
\begin{aligned}
& \pi_{i}(t)=p_{A}(t) q_{i A}(t)+p_{B}(t) \frac{q_{i B}(t)}{s_{i}(t)}-\beta\left[k_{i}(t)\right]^{2} \\
& \pi_{j}(t)=p_{B}(t) q_{j B}(t)+p_{A}(t) \frac{q_{j A}(t)}{s_{j}(t)}-\beta\left[k_{j}(t)\right]^{2}
\end{aligned}
$$

where $k_{i}(t)$ and $k_{j}(t)$, respectively, represent the amount of effort made by firm $i$ and firm $j$ at time $t$ in order to reduce the percentage of quantity lost on the way. Parameter $\beta>0$ is an inverse measure of TCRD productivity.

As a result of such activities, each firm increases the fraction of good that reaches foreign market. We assume that $s_{i}(t)$ and $s_{j}(t)$ evolve over time according to the following kinematic equations:

$$
\begin{aligned}
& \dot{s}_{i}(t)=\frac{\partial s_{i}(t)}{\partial t}=\left[\alpha k_{i}(t)-\delta s_{i}(t)\right]\left[1-s_{i}(t)\right] \\
& \dot{s}_{j}(t)=\frac{\partial s_{j}(t)}{\partial t}=\left[\alpha k_{j}(t)-\delta s_{j}(t)\right]\left[1-s_{j}(t)\right]
\end{aligned}
$$

where $\delta \in[0,1]$ denotes the depreciation rate, which is common to both firms and constant over time; $\alpha>0$ is a constant parameter positively affecting the accumulation process. 
We assume that firm $i$ aims at maximizing the discounted profit flow:

$$
\Pi_{i}(t)=\int_{0}^{\infty} \pi_{i}(t) e^{-\rho t} d t
$$

w.r.t. controls $k_{i}(t)$ and the market variables $q_{i A}(t)$ and $q_{i B}(t)$, under the constraint given by the state dynamics (5). Firm $j$ follows a specular dynamic optimization program. The discount rate $\rho>0$ is assumed to be constant and common to both firms.

\section{Solution of the Game}

The current value Hamiltonian function for firm $i$ writes:

$$
\mathcal{H}_{i}=e^{-\rho t}\left\{\pi_{i}(t)+\lambda_{i i}(t) \dot{s}_{i}(t)+\lambda_{i j}(t) \dot{s}_{j}(t)\right\} d t
$$

where $\lambda_{i i}(t)=\mu_{i i}(t) e^{\rho t}$ and $\lambda_{i j}(t)=\mu_{i j}(t) e^{\rho t}, \mu_{i i}(t)$ being the co-state variable associated to $s_{i}(t)$. Firms play simultaneously. Firm $i$ 's first order conditions (FOCs) on controls are: ${ }^{4}$

$$
\begin{gathered}
\frac{\partial \mathcal{H}_{i}}{\partial q_{i I}}=0 \Rightarrow q_{i I}=\frac{1}{2}\left(a_{I}-\frac{q_{j I}}{s_{j}}\right) ; I=A, B \\
\frac{\partial \mathcal{H}_{i}}{\partial q_{i J}}=0 \Rightarrow q_{i J}=\frac{s_{i}}{2}\left(a_{J}-q_{j J}\right) ; J=A, B \\
\frac{\partial \mathcal{H}_{i}}{\partial k_{i}}=0 \Rightarrow \lambda_{i i}=\frac{2 \beta k_{i}}{\alpha\left(1-s_{i}\right)}
\end{gathered}
$$

along with the transversality and initial conditions:

$$
\lim _{t \rightarrow \infty} \mu_{i i} s_{i}=0, \quad s_{i}(0)>1 .
$$

Note that the above FOCs do not contain $\lambda_{i j}$, therefore we set $\lambda_{i j}=0$ for all $t \in[0, \infty)$. Moreover, (9) contains $s_{j}$, i.e., the state variable of the rival, meaning that the open-loop solution and the closed-loop memoryless solution do not coincide. Consequently, we deal with the two solution concepts.

\footnotetext{
${ }^{4}$ For the sake of brevity, in the remainder we omit the indication of time as well as exponential discounting.
} 


\subsection{Open-Loop Nash Equilibrium}

The outcome of the open-loop game is summarised by the following:

Proposition 1 The open-loop game reaches a unique steady state at:

$$
k_{i}^{O L}=\frac{\rho+\delta}{\alpha} ; \quad s_{i}^{O L}=\frac{\rho+\delta}{\delta} .
$$

The equilibrium $\left\{k_{i}^{O L}, s_{i}^{O L}\right\}$ is a saddle point.

Proof. Under the open-loop solution concept, we can specify the firm $i$ 's co-state equation as follows:

$$
\begin{gathered}
-\frac{\partial \mathcal{H}_{i}}{\partial s_{i}}=\dot{\lambda}_{i i}-\rho \lambda_{i i} \Leftrightarrow \\
\dot{\lambda}_{i i}=\frac{q_{i J}\left[s_{i}\left(a_{J}-q_{j J}\right)-2 q_{i J}\right]+\lambda_{i i}\left[\rho+\alpha k_{i}-\delta\left(2 s_{i}-1\right)\right] s_{i}^{3}}{s_{i}^{3}} .
\end{gathered}
$$

Now, by using (11), one obtains the dynamics of investment:

$$
\dot{k}_{i}=\frac{\alpha}{2 \beta}\left[\dot{\lambda}_{i i}\left(1-s_{i}\right)-\lambda_{i i} \dot{s}_{i}\right]
$$

which can be simplified by using the co-state equation (13) and the system (9-10):

$$
\dot{k}_{i}=k_{i}\left(\rho+\delta-\delta s_{i}\right)
$$

The steady state equilibrium requires $\left\{\dot{k}_{i}=0, \dot{s}_{i}=0\right\}$, yielding:

$$
k_{i}^{O L}=\frac{\rho+\delta}{\alpha} ; \quad s_{i}^{O L}=\frac{\rho+\delta}{\delta}
$$

Since under open-loop solution concept, by definition, feedback effects are not accounted for, the equilibria we find are such that the size of the country does not play any role. Indeed, $k_{i}^{O L}$ and $s_{i}^{O L}$ depend only upon intertemporal parameters. ${ }^{5}$

As to the issue of stability, on the basis of symmetry, we can look at a single firm in isolation. Using the two differential equations (5) and (15), we can write the Jacobian matrix of firm $i$ :

\footnotetext{
${ }^{5}$ This can be shown to hold as well in a similar setup without trade (see Colombo, Lambertini and Mantovani, 2003).
} 


$$
J^{O L}=\left[\begin{array}{cc}
\frac{\partial \dot{s_{i}}}{\partial s_{i}} & \frac{\partial \dot{s_{i}}}{\partial k_{i}} \\
\frac{\partial \dot{k}_{i}}{\partial s_{i}} & \frac{\partial \dot{k}_{i}}{\partial k_{i}}
\end{array}\right]=\left[\begin{array}{cc}
-\delta+2 \delta s_{i}-\alpha k_{i} & \alpha\left(1-s_{i}\right) \\
-\delta k_{i} & \rho+\delta-\delta s_{i}
\end{array}\right]
$$

The trace and determinants of $J^{O L}$ are:

$$
\begin{gathered}
\operatorname{Tr}\left(J^{O L}\right)=\rho+1-\delta>0 \\
\Delta\left(J^{O L}\right)=\rho \delta\left(2 s_{i}-1\right)-\alpha \rho k_{i}+\delta^{2}\left[s_{i}\left(3-2 s_{i}\right)-1\right]
\end{gathered}
$$

which, evaluated at $\left\{k_{i}^{O L}, s_{i}^{O L}\right\}$, simplifies as follows:

$$
\Delta\left(J^{O L}\right)=-\rho(\rho+\delta)<0 .
$$

This concludes the proof.

Equilibrium outputs are:

$$
\begin{aligned}
& q_{i A}^{O L}=\frac{a_{A}}{3} ; q_{i B}^{O L}=\frac{a_{B} s_{i}^{O L}}{3}=\frac{a_{B}(\rho+\delta)}{3 \delta} ; \\
& q_{j A}^{O L}=\frac{a_{A} s_{j}^{O L}}{3}=\frac{a_{A}(\rho+\delta)}{3 \delta} ; q_{j B}^{O L}=\frac{a_{B}}{3} ;
\end{aligned}
$$

while profits are:

$$
\pi_{i}^{O L}=\frac{a_{A}^{2}+a_{B}^{2}}{9}-\frac{\beta(\rho+\delta)^{2}}{\alpha^{2}}>0 \text { iff } \frac{a_{A}^{2}+a_{B}^{2}}{9}>\frac{\beta(\rho+\delta)^{2}}{\alpha^{2}} .
$$

\subsection{Closed-Loop Nash Equilibrium}

Here we take into account the feedback between player $i$ 's strategy and player $j$ 's state variable. This will lead to an equilibrium characterized by subgame perfection.

We specify the firm $i$ 's co-state equation:

$$
-\frac{\partial \mathcal{H}_{i}}{\partial s_{i}}-\frac{\partial \mathcal{H}_{i}}{\partial q_{j J}} \frac{\partial q_{j J}^{*}}{\partial s_{i}}=\dot{\lambda}_{i i}-\rho \lambda_{i i}
$$

along with the transversality and initial conditions:

$$
\lim _{t \rightarrow \infty} \mu_{i i} s_{i}=0, \quad s_{i}(0)>1 .
$$


The partial derivatives appearing in (19) are:

$$
\begin{gathered}
\frac{\partial \mathcal{H}_{i}}{\partial s_{i}}=\frac{2 q_{i J}^{2}-q_{i J}\left(a_{J}-q_{j J}\right) s_{i}+\lambda_{i i}\left[\left(2 s_{i}-1\right) \delta-\alpha k_{i}\right] s_{i}^{3}}{s_{i}^{3}} \\
\frac{\partial \mathcal{H}_{i}}{\partial q_{j J}}=-\frac{q_{i J}}{s_{i}} ; \frac{\partial q_{j J}^{*}}{\partial s_{i}}=\frac{q_{i J}}{2 s_{i}^{2}}
\end{gathered}
$$

Optimal output levels are as in (17), i.e., $q_{i I}^{C L}=a_{I} / 3$ and $q_{i J}^{C L}=a_{J} s_{i}^{C L} / 3$. Now, by using (14), (17) and the co-state equation (19), we can write:

$$
\dot{k}_{i}=\frac{36 \beta k_{i} s_{i}\left(\rho-\delta s_{i}+\delta\right)-a_{j}^{2}\left(s_{i}-1\right) \alpha}{36 \beta s_{i}}
$$

However, steady state solutions are cumbersome, therefore they cannot be intuitively interpreted. Hence, we proceed as follows. We impose $\dot{k}_{i}=0$ to determine an equilibrium relation between $k_{i}$ and $s_{i}$ :

$$
k_{i}^{C L}\left(s_{i}\right)=\frac{a_{J}^{2}\left(s_{i}-1\right) \alpha}{36 \beta s_{i}\left[\rho-\delta\left(s_{i}-1\right)\right]}
$$

Notice that, here, steady state expressions involve the size of the countries as well as parameter $\beta$, unlike what we have observed in the previous section, treating the open-loop solution. Indeed, $k_{i}^{O L}$ and $s_{i}^{O L}$ depend only on intertemporal parameters, while $k_{i}^{C L}$ and therefore also $s_{i}^{C L}$ are explicitly affected by the size of the foreign market as well as the efficiency of R\&D activity, as (inversely) measured by the cost parameter $\beta$. This clearly reflects the fact that the closed-loop solution conveys more information than the open-loop one, by explicitly taking into account the rival's reaction.

The following can be shown to hold:

Proposition 2 The steady state defined by $\left\{\dot{k}_{i}=0, \dot{s}_{i}=0\right\}$ is a saddle point.

Proof. See the Appendix.

An intuitive illustration of saddle point stability can be obtained from the phase diagram of firm $i$, as it is described in Figure 1. 
Figure 1 : The phase diagram for firm $i$

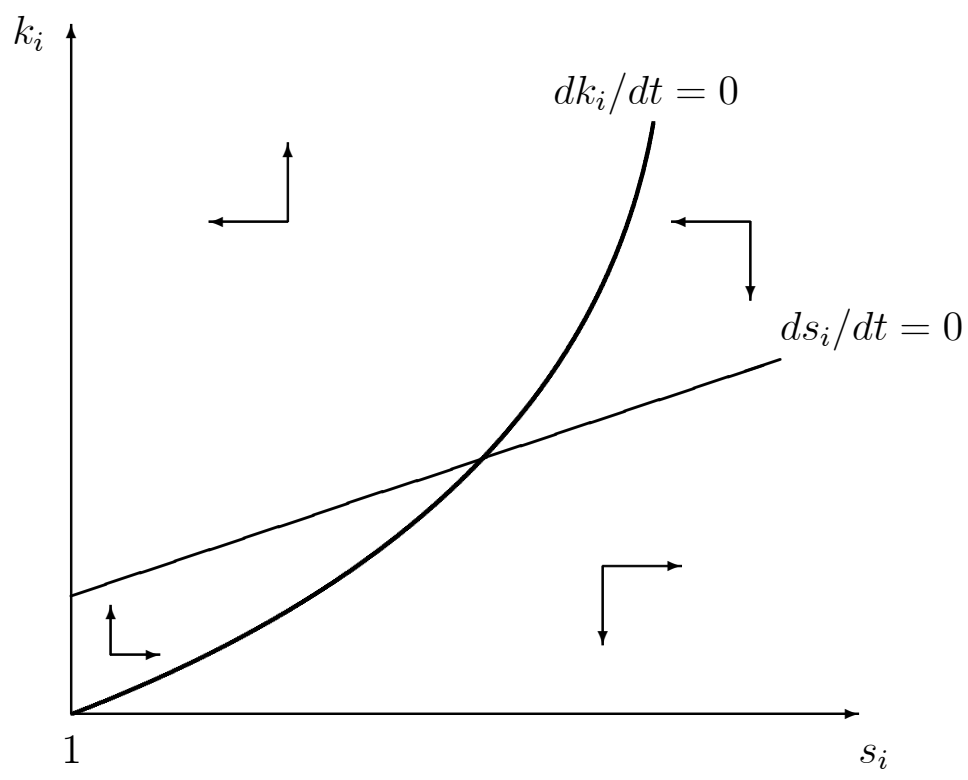

Some intuitive comparative statics can be carried out on $k_{i}^{C L}\left(s_{i}\right)$ :

$$
\frac{\partial k_{i}^{C L}\left(s_{i}\right)}{\partial \alpha}>0 ; \frac{\partial k_{i}^{C L}\left(s_{i}\right)}{\partial \beta}<0
$$

More interesting is the following:

$$
\frac{\partial k_{i}^{C L}\left(s_{i}\right)}{\partial a_{J}}>0
$$

which tells that the locus of the optimal investment shifts upwards with the size of the foreign market. We can label this as the foreign market effect: the larger is the foreign market, the higher is the incentive to carry out $R \& D$ activity to improve the efficiency of transportation, for any given level of the iceberg cost $s_{i}$. However, we are about to show that, in equilibrium, any upward shift of the locus $\dot{k}_{i}=0$ brings about a decrease in the steady state investment, due to the shape of $\dot{s}_{i}=0$.

Moreover, from (24), we also draw the following implication: 
Lemma 3 The condition $s_{i}=s_{j}$, is sufficient to ensure that, along the path to the steady state, $k_{i}^{C L}>k_{j}^{C L}$ for all $a_{I}<a_{J}$, and conversely.

The effect of $s_{i}$ on $k_{i}^{C L}\left(s_{i}\right)$ is also relevant:

$$
\frac{\partial k_{i}^{C L}\left(s_{i}\right)}{\partial s_{i}}=\frac{a_{J}^{2}\left[\rho+\delta\left(s_{i}-1\right)^{2}\right] \alpha}{36 \beta s_{i}^{2}\left[\rho-\delta\left(s_{i}-1\right)\right]^{2}}>0,
$$

which proves the following:

Lemma 4 The locus of the optimal investment in TCRD, $k_{i}^{C L}\left(s_{i}\right)$, shifts upwards for any given increase in $s_{i}$.

This is due to the fact that, the smaller is the fraction of exports that can actually reach the foreign market, the higher is the incentive for firm $i$ to invest in order to improve the efficiency of the transportation technology.

We are now in a position to derive the implicit profit levels (for a given level of $s_{i}$ ) under the closed-loop solution concept. Before doing this, from a direct comparison between (16) and (24), it is easy to prove that the optimal effort in TCRD is higher under the closed-loop than under the open-loop solution (see Colombo, Lambertini and Mantovani, 2003).

This result is in line with the kind of $R \& D$ activity at stake, which aims at increasing the percentage of output that reaches the foreign market. Moreover, we confirm the conventional wisdom that firms invest more when using closed-loop decision rules than open-loop ones (see, e.g., Reynolds, 1987).

The steady state profits accruing to firm $i$ are:

$$
\pi_{i}^{C L}\left(s_{i}\right)=\frac{a_{I}^{2}+a_{J}^{2}}{9}-\frac{a_{J}^{4}\left(s_{i}-1\right)^{2} \alpha^{2}}{1296 \beta s_{i}^{2}\left[\rho-\delta\left(s_{i}-1\right)\right]^{2}}
$$

Proposition 5 If $a_{I} \geq a_{J}$ then $s_{i}^{C L}>s_{j}^{C L}$ and $k_{i}^{C L}>k_{j}^{C L}$.

Proof. First, we plug $k_{i}^{C L}\left(s_{i}\right)$ into $\dot{s}_{i}$ and impose $\dot{s}_{i}=0$, to get:

$$
s_{i}^{C L}=\frac{\rho+\delta}{3 \delta}+\frac{3 \beta \delta^{2} \Psi+\sqrt[3]{(\Phi+\sqrt{3 \Theta})^{2}}}{18 \beta \delta^{2} \sqrt[3]{\Phi+\sqrt{3 \Theta}}}
$$


where:

$$
\begin{gathered}
\Psi \equiv 12 \beta(\rho+\delta)^{2}-\alpha^{2} a_{J}^{2} \\
\Phi \equiv 27 \beta^{2} \delta^{3}\left[8 \beta(\rho+\delta)^{3}-\alpha^{2} a_{J}^{2}(\rho-2 \delta)\right] \\
\Theta \equiv \beta^{3} \delta^{6}\left\{27 \beta\left[8 \beta(\rho+\delta)^{3}-\alpha^{2} a_{J}^{2}(\rho-2 \delta)\right]^{2}-\left[12 \beta(\rho+\delta)^{2}-\alpha^{2} a_{J}^{2}\right]^{3}\right\} .
\end{gathered}
$$

Now it can be checked that $s_{i}^{C L}=s_{j}^{C L}$ at $a_{I}=a_{J}$, while $s_{i}^{C L}>s_{j}^{C L}$ for all $a_{I}>$ $a_{J}$ (and conversely). Then, from (5-6), notice that one can write $k_{i}^{C L}=\delta s_{i}^{C L} / \alpha$. Therefore, if $s_{i}^{C L}>s_{j}^{C L}$, then it must be true that $k_{i}^{C L}>k_{j}^{C L}$.

The above proposition states that, in steady state, the firm located in the larger country has a comparatively higher incentive to invest in TCRD than the firm located in the smaller country. We label this as the home market effect. While the foreign market effect outlined above matters along the path to the steady state, the home market effect emerges in steady state only. The explanation is the following. Along the optimal investment path, the firm focusses its efforts upon the attempt to improve its ability to export, i.e., what matters is the size of the other country. This is represented by the fact that $k_{i}^{C L}\left(s_{i}\right)$ is a function of $a_{J}$ but not of $a_{I}$. In steady state, firms only invest in order to preserve the equilibrium, i.e., the status quo. In this situation, firm $i$ 's ability to invest so as to make up for the depreciation rate ultimately depends upon its capacity to raise resources to finance R\&D activity. This is essentially determined by its domestic market. In this sense, the features of the steady state equilibrium recall the well known home effect already highlighted in the existing literature (Helpman and Krugman, 1985; Krugman, 1990).

The foregoing analysis can be described graphically, by referring to Figure 2. 
Figure 2 : The phase diagram drawn for $a_{I}>a_{J}$

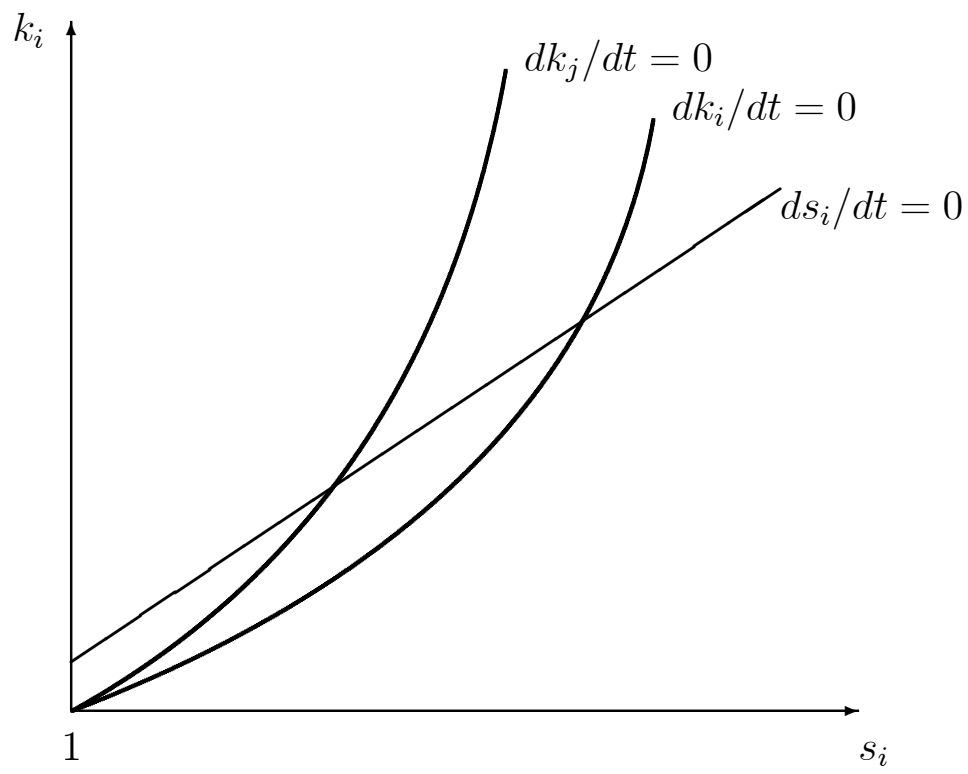

In the figure, we assume $a_{I}>a_{J}$, so that the locus $\dot{k}_{i}=0$ lies everywhere to the right of $\dot{k}_{j}=0$, and below it. then, note that a unique locus $\dot{s}_{i}=0$ appears, in that the parameters affecting the state dynamics are fully symmetric across firms. Therefore, the inequality $a_{I}>a_{J}$ directly implies both $k_{i}^{C L}>k_{j}^{C L}$ and $s_{i}^{C L}>s_{j}^{C L}$.

\section{Policy Implications at the Closed-Loop Equilib- rium}

The social welfare enjoyed by country $I$ in the steady state associated with the closedloop equilibrium is:

$$
S W_{I}^{C L}=\pi_{i}^{C L}+C S_{I}^{C L}
$$


where $C S_{I}^{C L}$ is the instantaneous consumer surplus:

$$
C S_{I}^{C L}=\frac{\left[a_{I}-p_{i}^{C L}\right]}{2} \cdot\left[q_{i I}^{C L}+\frac{q_{j I}^{C L}}{s_{j}}\right]=\frac{2 a_{I}^{2}}{9}
$$

and $\pi_{i}^{C L}$ is given by (27). Therefore, welfare can be written for a generic $s_{i}$, as follows:

$$
S W_{I}^{C L}\left(s_{i}\right)=\frac{a_{I}^{2}}{3}+\frac{a_{j}^{2}}{9}-\frac{a_{J}^{4}\left(s_{i}-1\right)^{2} \alpha^{2}}{1296 \beta s_{i}^{2}\left[\rho-\delta\left(s_{i}-1\right)\right]^{2}}
$$

We want to investigate the responses of $S W_{I}^{C L}\left(s_{i}\right)$ to different policy measures. Assume that the government of country I may choose between two kinds of policies: (i) an $\mathrm{R} \& \mathrm{D}$ subsidy to affect the instantaneous investment costs, through a reduction of $\beta$; (ii) an $R \& D$ subsidy affecting the accumulation process, through an increase of $\alpha$. Consider, first, policy (i). Its marginal effect on welfare is given by:

$$
\frac{\partial S W_{I}^{C L}\left(s_{i}\right)}{\partial \beta}=\frac{a_{J}^{4}\left(s_{i}-1\right)^{2} \alpha^{2}}{1296 \beta^{2} s_{i}^{2}\left[\rho-\delta\left(s_{i}-1\right)\right]^{2}}>0
$$

Therefore, a marginal increase in $\beta$ improves welfare. This can be explained as follows. An increase in $\beta$ reduces $k_{i}^{C L}\left(s_{i}\right)$, as we know from (25). This suggests that firms invest too much in $R \& D$ as compared to what would be socially optimal, given the output levels chosen on the basis of profit maximisation.

As to policy (ii), its effect is given by:

$$
\frac{\partial S W_{I}^{C L}\left(s_{i}\right)}{\partial \alpha}=-\frac{a_{J}^{4}\left(s_{i}-1\right)^{2} \alpha}{648 \beta s_{i}^{2}\left[\rho-\delta\left(s_{i}-1\right)\right]^{2}}<0
$$

Likewise, a marginal decrease in $\alpha$ yields a welfare improvement, since it slows down the R\&D investment.

In line of principle, the two measures could obviously be implemented together. However, this may not be possible. In order to understand which one should be preferred, we consider the following:

$$
\left|\frac{\partial W_{I}^{C L}\left(s_{i}\right)}{\partial \alpha}\right|=\frac{2 \beta}{\alpha}\left|\frac{\partial W_{I}^{C L}\left(s_{i}\right)}{\partial \beta}\right|
$$

It is immediate to draw from it: 
Proposition 6 For all $\beta>\alpha / 2$, it is preferable to reduce the investment efforts of firms by reducing the productive efficiency of R\&D activity, rather than increasing the cost of RGD investment, and vice versa.

That is, a welfare-improving reduction of excess investment typically emerging in Cournot markets (as in Brander and Spencer, 1983; Spencer and Brander, 1983), can be attained through several forms of taxation, affecting either the perceived cost of $\mathrm{R} \& \mathrm{D}$ activity to be accounted for in instantaneous profits (parameter $\beta$ ), or the performance of $\mathrm{R} \& \mathrm{D}$ activity itself (parameter $\alpha$ ).

\section{Concluding remarks}

We have analysed a dynamic Cournot duopoly with intraindustry trade, where firms invest so as to reduce the level of iceberg transportation costs. We have derived both open-loop and closed-loop equilibria, showing that a unique (saddle point) steady state exists in both cases. In the open-loop model, optimal investments and the resulting efficiency of transportation technology are independent of the relative size of the two countries. On the contrary, in the closed-loop case, a home market effect operates so that the firm located in the larger country invests more than the rival located in the smaller one.

In order to reduce the excessive amount of $\mathrm{R} \& \mathrm{D}$ effort by the domestic firm, a policy maker aiming at enhancing domestic social welfare may adopt two different types of R\&D taxation, or a mix thereof. 


\section{Appendix}

Proof of Proposition 2. The dynamic system is described by the following differential equations:

$$
\begin{gathered}
\dot{k}_{i}=\frac{36 \beta k_{i} s_{i}\left(\rho-\delta s_{i}+\delta\right)-a_{j}^{2}\left(s_{i}-1\right) \alpha}{36 \beta s_{i}} \\
\dot{s}_{i}=\frac{\partial s_{i}(t)}{\partial t}=\left[\alpha k_{i}-\delta s_{i}\right]\left[1-s_{i}\right]
\end{gathered}
$$

yielding the Jacobian matrix for the closed-loop case:

$$
J^{C L}=\left[\begin{array}{ll}
\frac{\partial \dot{k}_{i}}{\partial k_{i}} & \frac{\partial \dot{k}_{i}}{\partial s_{i}} \\
\frac{\partial \dot{s}_{i}}{\partial k_{i}} & \frac{\partial \dot{s}_{i}}{\partial s_{i}}
\end{array}\right]=\left[\begin{array}{cc}
\rho-\delta s_{i}+\delta & -\frac{36 \beta k_{i} s_{i}^{2} \delta+a_{j}^{2} \alpha}{36 \beta s_{i}^{2}} \\
-\alpha\left(s_{i}-1\right) & -\delta+2 \delta s_{i}-\alpha k_{i}
\end{array}\right]
$$

The determinant of $J^{C L}$ is:

$$
\Delta\left(J^{C L}\right)=-\frac{36 \beta s_{i}^{2}\left(\rho \delta-2 s_{i} \rho \delta+\rho \alpha k_{i}-3 s_{i} \delta^{2}+2 s_{i}^{2} \delta^{2}+\delta^{2}\right)+a_{j}^{2} \alpha^{2}\left(s_{i}-1\right)}{36 \beta s_{i}^{2}}
$$

and $\left\{k_{i}^{C L}, s_{i}^{C L}\right\}$ is a saddle point if $\Delta\left(J^{C L}\right)<0$. Now, from (24), one can plug $k_{i}^{C L}\left(s_{i}\right)$ into (a4) to obtain:

$$
\Delta\left(J^{C L}\right)=-\frac{\alpha^{2} a_{j}^{2}(\rho+\delta)\left(s_{i}-1\right)^{2}-36 \beta \delta s_{i}^{2}\left(2 s_{i}-1\right)\left(\rho+\delta-\delta s_{i}\right)^{2}}{\rho+\delta-\delta s_{i}} .
$$

The non-negativity of $(24)$ requires $s_{i}<(\rho+\delta) / \delta$, i.e., the open-loop solution for $s_{i}$. Therefore, in general, we can write:

$$
s_{i}=\frac{\rho+\delta-\varepsilon}{\delta}
$$

where $\varepsilon$ is positive and small. In correspondence of (a6), the determinant rewrites as:

$$
\Delta\left(J^{C L}\right)=-\frac{\alpha^{2} a_{j}^{2}(\rho+\delta)(\varepsilon-\rho)^{2}-36 \beta \varepsilon^{2}(\rho+\delta-\varepsilon)(2 \rho+\delta-2 \varepsilon)}{\delta^{2}}
$$

with

$$
\lim _{\varepsilon \rightarrow 0}=-\frac{\alpha^{2} a_{j}^{2}(\rho+\delta) \rho^{2}}{\delta^{2}}<0
$$

which proves that, in the left neighbourhood of the open-loop solution for $s_{i}$, the closed-loop equilibrium is a saddle point. Alternatively, one can plug (28) into (a5) 
and give plausible numerical values to $\left(a_{j}, \alpha, \beta\right)$, to verify that $\Delta\left(J^{C L}\right)<0$ for all $\delta, \rho \in[0,1]$.

Concerning the second order conditions, we apply Arrow's sufficiency theorem (1968); see also Chiang (1992, ch. 8). The Hessian matrix of firm $i$ is:

$$
H_{i}=\left[\begin{array}{ll}
\frac{\lambda_{i i}}{2}\left(\frac{\alpha^{2} \lambda_{i i}}{b}+4 \delta\right) & 0 \\
0 & \frac{\alpha^{2} \lambda_{i j} \lambda_{j j}}{b}+2 \lambda_{i j} \delta
\end{array}\right]
$$

Since the determinant of the above $2 \times 2$ matrix is positive, the matrix is negative definite. Hence, second order conditions are satisfied. 


\section{References}

[1] Anderson, J.E. and Marcouiller, D. (1999) Trade, insecurity, and home bias. An empirical investigation. NBER working paper no. 7000.

[2] Arrow, K.J. (1968) Applications of control theory to economic growth. In Dantzig, G.B. and A.F. Veinott, Jr (eds), Mathematics of the decision sciences, Part 2, American Mathematical Society, Providence, RI.

[3] Brander, J. (1981) Intra-industry trade in identical commodities. Journal of International Economics, 11, 1-14.

[4] Brander, J. and Spencer, B. (1983) Strategic commitment with R\&D: the symmetric case. Bell Journal of Economics, 14, 225-235.

[5] Cellini, R. and Lambertini, L. (2003) Differential oligopoly games. Technology, Information and Market Dynamics: Topics in Advanced Industrial Organization, eds P. Bianchi and L. Lambertini, pp. 173-207. Edward Elgar, London.

[6] Chiang, A.C. (1992) Elements of dynamic optimization. McGraw-Hill, New York.

[7] Colombo, L., Lambertini, L. and A. Mantovani (2003), A Differential Game with Investments in Transport and Communication R\&D, Working Paper $\mathrm{n}$. 466, Dipartimento di Scienze Economiche, Università degli Studi di Bologna.

[8] Dockner, E.J., Jorgensen, S., Long, N.V. and Sorger, G. (2000) Differential games in economics and management science. Cambridge University Press, Cambridge.

[9] Harley, C. (1980) Transportation, the world wheat trade and the Kuznets cycle, 1850-1913. Explorations in Economic History, 17, 218-250.

[10] Helpman, E. and Krugman, P. (1985) Market structure and foreign trade. MIT Press, Cambridge MA. 
[11] Krugman, P. (1990) Rethinking international trade. MIT Press, Cambridge, MA.

[12] Lambertini, L., Mantovani, A. and Rossini, G. (2003) R\&D in Transport and Communication in a Cournot Duopoly, Rivista Internazionale di Scienze Economiche e Commerciali, forthcoming.

[13] McCallum, J. (1996) National borders matter: Canada-US regional trade patterns. American Economic Review, 85, 615-623.

[14] Obstfeld, M. and Rogoff, K. (2000) The six major puzzles in international macroeconomics: is there a common cause? NBER working paper no. 7777.

[15] O'Rourke, K.H. and Williamson, J.G. (1999) Globalization and history. The evolution of the nineteenth century atlantic economy. MIT Press, Cambridge, MA.

[16] Reynolds, S.S. (1987) Capacity investment, preemption and commitment in an infinite horizon model. International Economic Review, 28, 69-88.

[17] Samuelson, P. (1954) The transfer problem and transport costs, II: Analysis of effects of trade impediments. Economic Journal, 64, 264-289.

[18] Spencer, B.J. and Brander, J.A. (1983) International R\&D rivalry and industrial strategy. Review of Economic Studies, 50, 707-722.

[19] Turrini, A. and van Ypersele, T. (2002) Traders, courts and the home bias puzzle. CEPR discussion paper no. 3228. 